\title{
Aqua-architecture as an autonomous system: metabolic components of the complete ecological cycle
}

\author{
Svetlana Kizilova ${ }^{1, *}$ \\ ${ }^{1}$ Moscow Architectural Institute (State Academy), Department "Fundamentals of Architectural \\ Design”, 107031 Rozhdestvenka st. 11/4, building 1. p. 4, Moscow, Russian Federation
}

\begin{abstract}
The article is devoted to the analysis of aqua-architecture's key components, providing autonomous functioning of a floating structure as an artificial full-cycle ecosystem. The leading approach to the study is a systematic analysis of the stages maintaining the complete ecological cycle: production of primary products, energy storage, waste management and operation control. The analysis of each stage is accompanied by the examples of built and conceptual projects of architectural structures on the water from the world's architectural practice. The research shows that it is necessary to include the production systems based on the usage of water resources at every stage. At the stage of primary products and water obtainment, it is advisable to provide aeroponic, aquaponic, hydroponic farms and water desalination plants. To obtain energy in the autonomous structure, it is necessary to organize floating solar farms, underwater hydropower and wind turbines. The disposal stage involves the installation of biogas facilities, hydro-botanical ponds and waste recycling systems. The fourth component of the full ecological cycle is smart management, the automation of which allows the whole system to function independently at any stage. Water resources can also be involved in transport and logistics processes as well as in microclimate maintenance. The materials of this study will be useful for further theoretical and practical developments in the field of eco-sustainable design in the extreme environments.
\end{abstract}

\section{Introduction}

Global climate changes associated with the general increase of the sea level and the upsurge of natural hydrometeorological phenomena require a review of traditional design solutions in the contemporary architectural practice. There is a growing demand for the design practice taking into account constantly changing environmental conditions. These processes lead to the formation of aqua-architecture, a receptive architectural typology that could provide flexible, safe and adaptable spaces for society. Since architectural objects on floating bases are in close contact with the ecosystems of water bodies, it is necessary to

*Corresponding author: s.kizilova@markhi.ru 
take into account the principles of eco-sustainability during the phases of design, construction and operation.

Aspects of spatial organization of architectural objects in the aquatic environment were considered in the works of several russian researchers: N. A. Saprykina, I. S. Ekonomov, A. L. Gelfond, O. A. Rodina, O. R. Shumskaya, as well as foreign scientists: K. K. Ashraf, K. Olthuis, P. Friedman, S. Al, A. F. Blumberg [1-5]. International architectural studios "Baca Architects", "Waterstudio", "Bjarke Ingels Group", "Carl Turner Architects", "Forum Studio" are engaged in the design and implementation of adaptive multifunctional structures in contact with the water environment [6-8]. However, recent theoretical studies have not sufficiently covered the leading processes of buildings' internal system operation in conditions of the autonomous life on the water.

The largest ecosystem of the Earth, the biosphere, is characterized by such features as integrity, centrality, stability, self-regulation, rhythm, circulation of substances and energy, zoning and diversity of species. Complex processes of constant migration of substances called metabolism, occurring in the ecosystem, form its characteristic properties [9]. The purpose of this study is to identify the ways to implement natural metabolic processes within an enclosed architectural system immersed in the aquatic medium.

\section{Materials and Methods}

The leading method of this study is the systematic analysis of the metabolic process in the architectural ecosystem subdivided into four main functions: extraction of raw material and water, energy production, waste disposal and life support system's automation within the framework of the autonomous existence.

\subsection{Primary products and fresh water obtainment}

The proximity of water resources indicates the prospects for the organization of farms within the spatial structure of an aquatic architectural object, using modern hydroponic technologies for growing crops.

The hydroponic method allows to grow crops in the tank of oxygenated water or in a porous filler without using any soil. This technology was implemented into the modular expo-farm "Jellyfish Barge", designed to supply riverine neighbourhoods with fresh products. In the aeroponic farms, plants are arranged vertically with an open root system, which is nourished with minerals by automated aerosol spraying. The aeroponic method allows to isolate plants from pathogenic bacteria and pests contained in the soil and contributes to a healthy harvest [10].

Aeroponic greenhouses are already used in some traditional buildings, for example, in the design of a recently built restaurant in Denver (Colorado, USA). On the second floor of the building there is a vegetable farm supplying fresh produce for the restaurant on the ground floor. The project "Skyfarm" by Roger Stirk Harbor + Partners architectural studio provides the location of aeroponic and aquaponic farms within the structure of a high-rise hyperboloid building. Farms are located on the upper floors, supplying a market and a restaurant on the ground floor.

Modern aquaponic farms combine both cultivation of fish and hydroponic crops by arranging interconnected artificial ponds. Crops receive nutrients from the water, which contains bacteria from fish waste products. At the end of the cycle, the water returns to the pond in its purified form.

The "Farming Architects" studio carried out the project of an aquaponic farm for the city of Hanoi (Vietnam), combining a wooden frame structure with a pond for growing 
local "koi" carps. The building is also used as a children's library: containers for books are placed in the modular grid.

In the context of the formation of floating agricultural structures, breeding larger animals becomes possible too. Engineer P. Van Wingerden (Beladon) designed an urban floating dairy farm in Rotterdam, which runs livestock breeding.

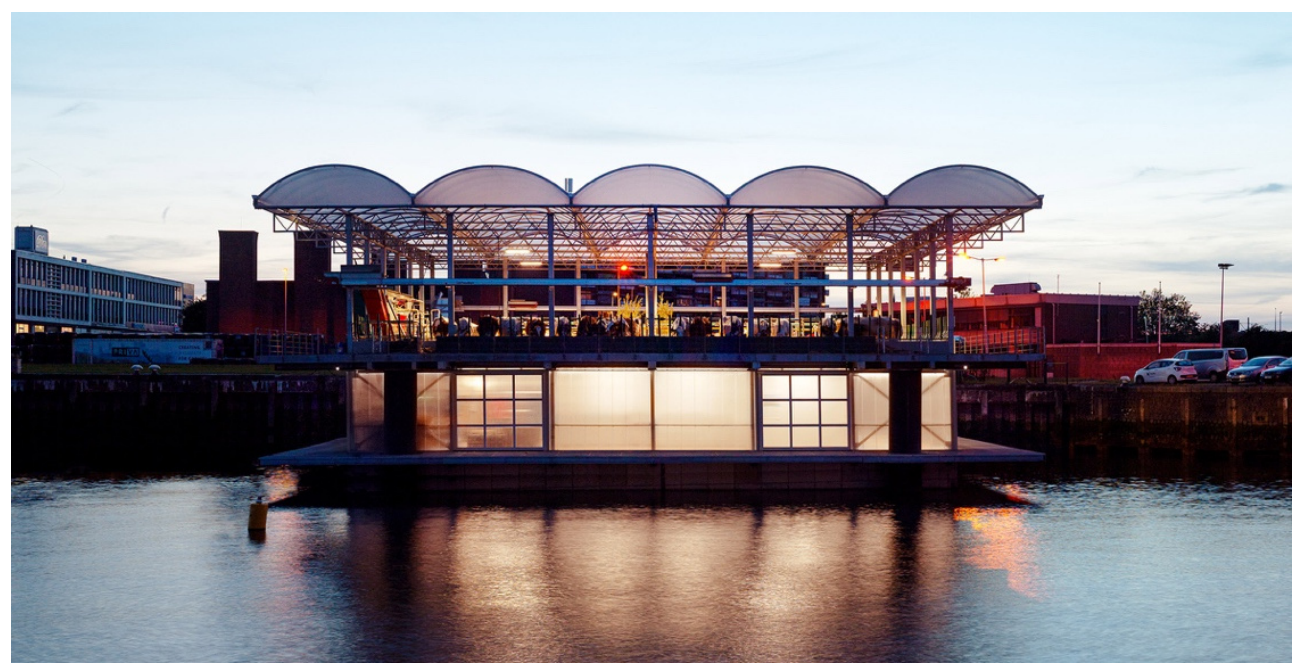

Fig. 1. Floating milk farm in Rotterdam (https://www.dezeen.com/2019/05/24/floating-farmrotterdam-climate-change-cows-dairy/).

Desalination of water in technological facilities occurs through either distillation or freezing. The conceptual design of "Foram" bionic floating plant uses solar energy during the desalination process. Desalinated water is utilized to irrigate suspended plants integrated into the shell of the structure. Floating farm "Arctic Harvester", designed for autonomous life in the Arctic latitudes, uses meltwater from small icebergs congregated in the internal pool.

\subsection{Energy resources accumulation}

The provision of energy resources within the autonomous existence is possible through the use of renewable energy sources. The accumulation of energy of the sun, water and wind becomes possible due to the inclusion of solar panels, wind generators and water power turbines in the architectural structures.

One of the first floating power plants was built in Brazil in 1978 and was used as a pulp mill and a power plant. Subsequently, the energy potential of floating structures was revealed in a number of conceptual projects by the Japanese company Shimizu. In particular, the project of the inhabited structure "Ocean Spiral" was aimed at the search and development of deep-sea resources.

A floating solar power station of 160 thousand panels was built on the area of 86 hectares occupying the territory of an artificial shallow lake in Huainan (China). Due to cooling from the surface of the reservoir, reflecting the properties of water and the absence of dust, floating solar panels generate more electricity [11]. The "Artificial Lilies" conceptual project for Glasgow provides the floating solar panels resembling flower petals for the accumulation of renewable energy [12].

In 2014, the British architect F. Pauli developed «Sub-Biosphere 2» habitable module for the life under water in the context of the world's growing population. Eight spheres, 
"biomes", interconnected by sealed bridges, move along the vertical frame rails, converting the pressure difference at various depths into electricity for the life support systems' maintenance [13].

The project of pyramidal modular houses on the water "Wayaland" designed by architect P. P. Lazzarini provides solar panels and water turbines located under the buildings for energy supply. Floating modules are designed to accommodate residential and public facilities: hotels, shops, gyms and cinemas. The size of the main module is 54 by 54 $\mathrm{m}$ in plan and has 10 floors. Due to the significant potential construction costs $(350000$ euros per module according to the calculations of the project's author), at the beginning it is planned to build a smaller two-story module measuring 10 by $10 \mathrm{~m}$.

The multifunctional surface structure "Manta Ray", designed by architect V. Callebaut for the port of Seoul in 2017, combines the functions of a ship terminal, a city park and a methane processing plant. The total square of 3,500 $\mathrm{m}^{2}$ of photovoltaic panels is located on the biomorphic roof, and wind turbines are integrated into the park's landscape. The aim of the project is to adapt coastal areas to climate change and attract investments in the development of aquatic spaces, providing additional opportunities for urban agriculture and land reclamation.

\subsection{Waste products disposal}

Conversion of waste products into energy is possible through generating biogas based on recycled solid or liquid household waste. Recycling requires the installation of reactors and waste sorting points as a part of a multifunctional architectural structure. Water is used as a liquid for heating and carrying out the fermentation reaction. The "Smart Floating Farms" floating farm project, designed to be autonomously located away from the coast, provides biogas plants for energy production.

The hydro-botanical method involves the creation of artificial conditions for wastewater purification, simulating the natural ability for self-cleaning of wetlands. The cleaning process occurs due to the absorption of oxygen dissolved in water by microorganisms for the decomposition of organic substances [14]. This method was used in the project of the multi-story floating skyscraper "Dragonfly" by V. Callebaut. Reservoirs and drainage pools for purification are arranged within the vertical space-frame [15].

Reuse of plastic waste in the construction of new facilities can reduce the construction costs. The walls of the floating pavilion by No Architects studio, which received an award for its contribution to the ecological state of the region, are constructed of wooden waste and plastic collected in an urban environment. The design of a floating modular park in Rotterdam used plastic waste collected in river channels to create new environment [16].

\subsection{Automated life-support systems}

Integrated smart-systems make possible the automatization of production, consumption and disposal stages inside a building located in the extreme environment $[17,18]$. The global trend in the development of "smart" habitats is the creation of automated megacities in the places with extreme hydrometeorological conditions. The range of such smart settlements includes floating cities and settlements with integrated water infrastructure.

The recent illustration of such futuristic cities is the "Hydro-net" project developed for San Francisco (California, USA). The infrastructure of the city repeats the biological scheme based on the spatial rhizome. Communicating underground systems use the existing aquifer and geothermal sources to collect and distribute water and energy flows. Algae plantations will produce the hydrogen necessary for the functioning of ecological transport. It is planned to use nanotubes passing inside the walls of residential buildings as hydrogen 
storages. Automated dehumidifiers will solve the problem of strong fogs in the city [19, $20]$.

The creators of the "Hydro-net" project, IwamotoScott Architects, also developed the photosynthetic floating city X-Sea-TY. The walls of the buildings are planned to be used as a framework for the growth of algae, on the basis of which biofuel is produced. Ecosustainable landscape will contribute to air purification in the areas where the movable city is located, increasing the population of plants and animals in the urban environment [21].
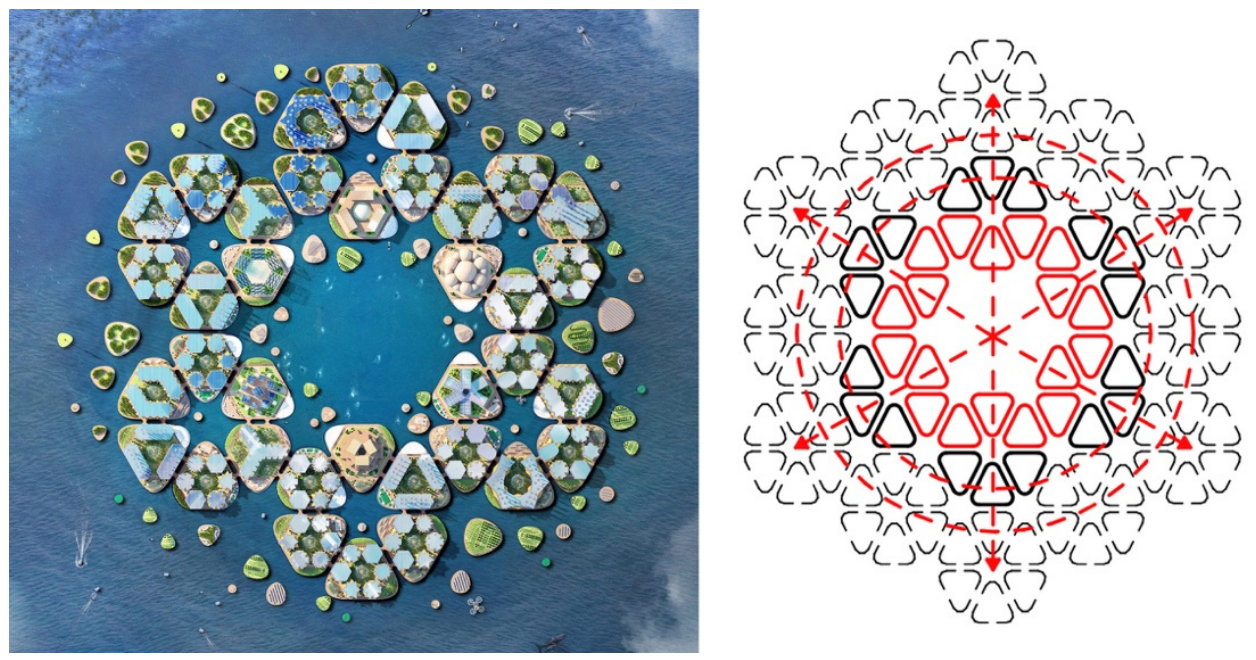

Fig. 2. "Oceanix City" by BIG. Masterplan (https://www.dezeen.com/2019/04/04/oceanixcity-floating-big-mit-united-nations/) and the growth strategy (figure by author).

In 2019 Bjarke Ingels Group architectural studio developed the "Oceanix City" floating islands project for 10,000 people. Mid-rise buildings constructed of environmentally friendly materials will be located on hexagonal platforms moored to the seabed. The modular structure develops the additivity principle: by adding islands from the centre to the periphery, a city of unlimited size is gradually formed from the small module. The floating infrastructure provides a system for garbage removal through pneumatic pipelines delivering wastes to the sorting and processing station.

The floating settlement consisted of hexagonal and triangular modules measuring 150 by $30 \mathrm{~m}$ was developed by AT Design Office for China. Prefabricated modules are organized around the inland pools serving as harbours for ecological maritime transport. At the same time, green belts, including gardens and production farms, pass over the surface and in the underwater part. The structure has multiple centres around which the main functional zones are grouped.

Emissions of toxic waste products and carbon dioxide in China in 2007 led to the idea of creating a self-sufficient eco-city Dongtan and four more satellite cities on the reclaimed territories in the middle of the river Yangtze. The design of an eco-city was also aimed at solving the problem of overpopulation and redistribution of jobs in Shanghai. It was planned to form a completely environmentally friendly infrastructure on the area of 8600 hectares by 2050. Arup Group company was involved in the development of the territory project. Systems for recycling waste, preserving the thermal energy of buildings and collecting rainwater were provided within the smart megapolis. It was also planned to use bicycles, electric and hydrogen vehicles as the main transportation sources [22]. 


\section{Results}

As a result of the analysis of the four metabolic components of the full ecological cycle and the examples of the implementation of production, utilization and automatic management within complex architectural systems, several statements were determined:

1 For the production of raw materials and fresh water resources in the context of aquaarchitecture, the following facilities are necessary:

- Hydroponic farms;

- Aeroponic farms;

- Aquaponic farms.

- Desalination plants.

2 For the accumulation of renewable energy in the conditions of autonomous existence on the water, it is vital to provide:

- Floating solar power plants;

- Wind generators;

- Tidal turbines.

3 For the disposal of waste in the enclosed floating structures, the following should be provided:

- Biogas plants;

- Hydro-botanical ponds;

- Waste recycling.

4 The presence of automated life support systems is necessary for the functioning of the three previous stages of the full ecological cycle. Through the automated energy collection, autonomous and continuous production of primary products is carried out with the subsequent disposal of waste. At the same time, automated systems should include:

- System for the collection and distribution of raw materials and energy;

- Transport and logistics system;

- Lighting and indoor climate control system.

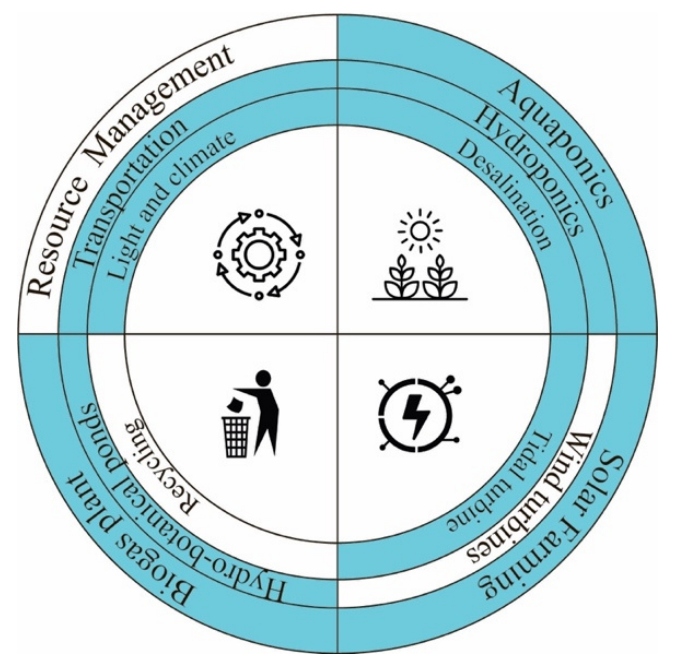

Fig. 3. The scheme of participation of water resources in the implementation of the full ecological cycle in aqua-architectural objects (figure by author).

The advantage and convenience of organizing architectural structures in the aquatic environment comes through the ability to use water resources to carry out the work of all stages: production, accumulation, disposal and management. The diagram (fig. 3) illustrates 
the production of the full ecological cycle, using water in the process of implementing their own functions. The facilities using water resources are highlighted with blue colour.

\section{Discussion}

The results will contribute to further theoretical research on the identification of the necessary conditions for life in the context of the aquatic environment. The revealed methods of organizing aqua-architectural objects like natural ecosystems are necessary for creating universal design and experimental models of aqua-architecture.

\section{Conclusion}

Effective organization of habitable space in an aquatic environment is possible due to the synthesis of four components associated with obtaining resources and energy, their utilization and management of life support systems. Control over cyclic processes will be carried out through the automated control systems. The design of innovative floating structures will allow the formation of an eco-sustainable production and consumption cycle in the future human habitat.

The reported study was funded by RFBR, project number 19-312-90008.

\section{References}

1. J. Quirk., P. Friedman, Seasteading: how floating nations will restore the environment, enrich the poor, cure the sick, and liberate humanity from politicians (Free Press, New York, 2017)

2. A. F. Blumberg, The Urban Ocean: The Interaction of Cities with Water (2018)

3. S. Al, Adapting Cities to Sea Level Rise: Green and Gray Strategies (2018)

4. C. Seavitt-Nordenson, G. Nordenson, J. Chapman, Structures of Coastal Resilience (2018)

5. H. Stopp, P. Strangfeld, Floating Architecture: Construction on and Near Water (LIT Verlag Dr. W. Hopf, Berlin, 2017)

6. K. Olthuis, D. Keuning, Float! Building on water to combat urban congestion and climate change (Frame Publishers, Amsterdam, 2010)

7. R. Barker, R.Coutts, Aquatecture: buildings designed to live and work with water (RIBA, London, 2016)

8. K.K. Ashraf, The Architectural Review, Fluid Space, 1443 (2017)

9. V. I. Vernadsky, The Biosphere (Springer Science \& Business Media, Berlin, 2012)

10. Sultanova A., Architecture and Modern Information Technologies, Innovative technologies and their influence on architectural design of plant growing buildings, $\mathbf{4 2}$ (2018)

11. Gamarra C., Ronk J. Texas Water Journal, Floating Solar: An Emerging Opportunity at the Energy-Water Nexus, 10 (2019)

12. N. A. Saprykina, Biosphere compatibility: people, region, technology, The paradigm of the ecological balance within of innovative concepts formation space habitats, $\mathbf{2 4}$ (2018) 
13. S. A. Kizilova, E3S Web of Conf., Form and functional features of modular floating structures, 91 (2019)

14. Bresciani R, Vestnik MGSU, Constructed wetland technology as an innovative water treatment method 14 (2019)

15. N. A. Saprykina, Formirovanie eko-ustojchivoj sredy obitaniya budushego: Teoriya, Praktika, Perspektivy (Palmarium Academic Publishing, Saarbrücken, 2017)

16. S. A. Kizilova, IOP Conf. Ser.: Mater. Sci. Eng., Maintenance characteristics of multifunctional industrial farms on the water in the context of the formation of the Advanced Development Territories in the Far Eastern Federal District (to be published)

17. N. A. Saprykina, IOP Conf. Ser.: Mater. Sci. Eng., The concept of organizing of the autonomous architectural objects as a new paradigm of habitat (to be published)

18. E. A. Belash, Innovation \& Investment, Ustojchivoe razvitie v structure processa proektirovaniya, 6 (2019)

19. N. A. Saprykina, IOP Conf. Ser.: Mater. Sci. Eng., Forecasting technology as a method of modeling and building Smart City concept, 365 (2018)

20. I. Berman, Architectural Design, Amphibious territories, 80 (2010)

21. S. A. Kizilova, IOP Conf. Ser.: Mater. Sci. Eng., Architectural facilities in the water environment as a perspective direction of the Far Eastern region development, $\mathbf{4 6 3}$ (2018)

22. H. Castle, Architectural Design, Dongtan, China's Flagship Eco-City, 78 (2008) 